\title{
Bedload transport and hydro-abrasive erosion at steep bedrock rivers and hydraulic structures
}

\author{
Michelle Mueller-Hagmann ${ }^{1,}$, Christian Auel ${ }^{2}$, Ismail Albayrak ${ }^{1}$ and Robert M. Boes ${ }^{1}$ \\ ${ }^{1}$ Laboratory of Hydraulics, Hydrology, and Glaciology (VAW), Swiss Federal Institute of Technology \\ Zurich (ETH Zurich), Zurich \\ ${ }^{2}$ ILF Consulting Engineers GmbH, Rum/Innsbruck, Austria
}

\begin{abstract}
Sediment transport in glacier basins and rivers, and hence reservoir sedimentation tend to increase under the impact of climate change. The raise of bedload transport rates results in an increase of hydro-abrasive erosion leading to bedrock incision in rivers and wear at hydraulic structures. Mechanistic abrasion models are a helpful tool for both river and landscape evolution and hydroabrasion of hydraulic structures. Therefore, knowledge of the physical processes of turbulent flow characteristics, bedload particle motion, and hydroabrasion and their interrelations is needed. Ongoing research at VAW of ETH Zurich aims at improving the required knowledge to address hydroabrasion issues by means of laboratory and prototype experiments in supercritical flows over fixed smooth and transitionally rough beds. A physical model investigation revealed that particle trajectories on fixed planar beds are rather symmetric, flat and long compared to alluvial beds. By applying newly developed particle motion equations, an existing mechanistic abrasion model was adapted and calibrated for concrete and natural rock by means of prototype data. This advances abrasion prediction modelling and contributes to a better understanding of river bed and landscape evolution and to a sustainable design and operation of hydraulic structures facing severe hydro-abrasive erosion.
\end{abstract}

\section{Introduction}

Sediment yield has significantly increased both in Alpine regions and worldwide due the strong impact of climate change and anthropogenic influences [1,2]. Retreating glaciers reveal fields of unconsolidated sediments subjected to high erosion rates [3]. The increase of discharge and its temporal variability raises the sediment transport capacity and, together with the increased sediment availability, effective sediment transport. High transport rates of bedload particles can cause severe abrasion such as bedrock incision in high-gradient mountain streams and hydro-abrasive erosion at hydraulic structures including dam outlets, weirs, Sediment Bypass Tunnels (SBT) and sediment flushing channels [4, 5, 6, 7]. The mechanics of both abrasion types are similar, and better understanding of the abrasion mechanics and developments of a realistic and mechanistic abrasion model are keys for design and sustainable use of such hydraulic structures and landscape evolution modelling.

\footnotetext{
* Corresponding author: Mueller-hagmann@,vaw.baug.ethz.ch
} 
Therefore, knowledge on flow characteristics, bedload particle motion, abrasion and their interactions in high-speed flows is needed.

Hydro-abrasive erosion is defined as the material loss on the surface of a solid body caused by mechanical stresses from impacts of water-carried particles [4]. Depending on the flow conditions, particles are transported in sliding, rolling or saltation mode causing different stresses on the bed. Saltation is the governing process causing hydro-abrasive erosion, whereas sliding and rolling do not cause significant wear $[5,6,8]$. The magnitude of abrasion increases with increasing specific energy transmitted from the particle to the bed, which is strongly controlled by the flow conditions, bedload transport characteristics, invert material properties and sediment particle size, shape and hardness $[5,6,9,10]$.

\section{Mechanistic abrasion modelling}

Sklar and Dietrich [5] expressed the magnitude of abrasion as a vertical abrasion rate and conducted abrasion experiments with various rock samples using a self-developed abrasion mill. They developed a physics-based abrasion model for bedrock incision depending on bed shear stress, bedrock erodibility, particle size, particle impact energy and sediment supply rate. The basic form of the saltation-abrasion model is:

$$
A_{r}=\frac{Y_{M}}{k_{v} f_{t}^{2}} \frac{W_{i m}^{2}}{L_{p}} q_{s}\left(1-\frac{q_{s}}{q_{s}^{*}}\right) \quad[\mathrm{m} / \mathrm{s}]
$$

where $A_{r}=$ vertical abrasion rate $[\mathrm{m} / \mathrm{s}], Y_{M}=$ Young's modulus $[\mathrm{Pa}], k_{v}=$ abrasion coefficient, $f_{t}=$ splitting tensile strength $[\mathrm{Pa}], W_{i m}=$ vertical particle impact velocity $[\mathrm{m} / \mathrm{s}]$, $L_{p}=$ particle hop length $[\mathrm{m}], q_{s}=$ specific gravimetric sediment transport rate $[\mathrm{kg} /(\mathrm{sm})]$, and $q_{s}{ }^{*}=$ specific gravimetric sediment transport capacity $[\mathrm{kg} /(\mathrm{sm})]$. The term $f_{t}^{2} /\left(2 Y_{M}\right)$ is called "elastic strain energy density" and represents the fracture energy required to detach a unit material volume. The second term denotes the flux of kinetic impact energy per unit area and time. The last term in round brackets is related to the cover effect that considers the fraction of exposed bedrock. Based on [11] Sklar and Dietrich [5] stated that the variation in $Y_{M}$ of rocks is limited and hence they treated it as a constant, i.e. $Y_{M}=50 \mathrm{GPa}$. This is actually a rough simplification and might be questioned regarding the large range of $Y_{M}$ at least for soft rocks and concretes.

The abrasion coefficient $k_{v}$ in Equation (1) is related to the efficiency of energy transfer from impinging particles to the invert material and is crucial for abrasion estimation. However, its determination is still a challenging issue of ongoing research. Sklar and Dietrich $[5,12]$ determined $k_{v}$ in a self-developed abrasion mill for various materials and proposed the widely accepted value of $k_{v}=10^{6}$ for rock, despite large variations of $k_{v}=1 \cdot 10^{6}$ to $9 \cdot 10^{6}$.

Auel et al. [13] recently published the results of a laboratory study on particle motion in high-speed flow. The test setup mimics non-alluvial high-gradient mountain streams and hydraulic structures with concrete or natural rock inverts, i.e. alluvial and planar beds. They proposed the following equations for the particle hop length $L_{p}$ and vertical impact velocity $W_{i m}$, differing from Sklar and Dietricht's [5] formulas:

$$
\begin{gathered}
L_{p}=2.3 \cdot T^{* 0.8} \cdot D \quad[\mathrm{~m}] \quad R^{2}=0.73 \\
W_{i m}=0.1 \cdot T^{* 0.39} \cdot \sqrt{(s-1) g D} \quad[\mathrm{~m} / \mathrm{s}] \quad R^{2}=0.69
\end{gathered}
$$

with the transport stage $T^{*}=\theta / \theta_{c}[-]$, the Shields parameter $\theta=U_{*}^{2} /[(s-1) g D][-]$, the friction velocity $U_{*}=\left(g \cdot R_{h} \cdot S\right)^{0.5}[\mathrm{~m} / \mathrm{s}]$, the ratio of solid to fluid density $s$ [-] (typically 2.65), the critical Shields parameter for particle motion $\theta_{c}[-]$ (which was found to be $\theta_{c}=0.005$ for fixed planar beds [13]), the gravity acceleration $g\left[\mathrm{~m} / \mathrm{s}^{2}\right]$, the hydraulic radius $R_{h}[\mathrm{~m}]$ and the energy line slope $S$ [-]. Replacing $L_{p}$ and $W_{i m}$ in Equation (1) and applying $T^{* 0.78} \approx T^{* 0.8}$ results in the adapted saltation-abrasion model according to Auel et al. [14]: 


$$
A_{r}=\frac{Y_{M}}{k_{v} f_{t}^{2}} \frac{(s-1) g}{230} q_{s}\left(1-\frac{q_{s}}{q_{s}^{*}}\right) \quad[\mathrm{m} / \mathrm{s}]
$$

Based on the measured abrasion depths of the concrete invert in a Japanese SBT, [14] determined $k_{v}=(1.9 \pm 0.7) \times 10^{5}$, which is roughly one order of magnitude lower compared to the value recommended by $[5,12]$ due to different particle motion formulas and Young's moduli. By considering also literature data of $[8,15$ and 16] encompassing both concrete and natural rock, [14] pointed out that $k_{v}$ is not a constant, but increases with splitting tensile strength as hypothesized by [17]. Moreover, $k_{v}$-values seem to scatter around a constant value for materials with $f_{t}>1 \mathrm{MPa}$ due to model uncertainties and a large range of investigated invert materials. Furthermore, angularity and hardness of sediment particles and invert material properties such as elastic strain energy, elasticity, density, porosity and crystal and clast size are demonstrated to affect $k_{v}$ and should be accounted for in hydroabrasion modelling [6, 18-24]. Overall, Equation (4) yields good results and therefore seems adequate for abrasion prediction for high-gradient mountains streams and hydraulic structures [14].

In general, both models (Equations 1 and 4) are calibrated based on comprehensive laboratory data and a few field data. As a consequence, upscaling of the small-scale results to the prototype scale is still questionable. In the present contribution, we address this question, extend the application range of the models to further invert materials, calibrate the abrasion coefficient and give insight into the abrasion patterns related to hydraulic conditions. To this end, hydro-abrasive erosion on the concrete and granite inverts implemented at the Pfaffensprung SBT in Switzerland was investigated under various hydraulic and sediment transport conditions from 2012 until 2015 [25]. In the following, test set-up and procedure are described, followed by the field results and conclusions.

\section{Field test setup and procedure}

\subsection{Location}

The Pfaffensprung reservoir is located on the Reuss River near Wassen, Canton Uri, in the Swiss Alps and has a capacity of $0.17 \cdot 10^{6} \mathrm{~m}^{3}$, which is quite small compared to the mean annual runoff of $645 \cdot 10^{6} \mathrm{~m}^{3}$ [26]. The mean particle size of the bed material is $d_{m}=0.25 \mathrm{~m}$, and the mean annual bedload transport =amounts to about 350'000 tons based on the estimations [25, 27]. The reservoir is equipped with a $282 \mathrm{~m}$ long and $4.4 \mathrm{~m}$ wide SBT (Fig. 1). The design discharge is $220 \mathrm{~m}^{3} / \mathrm{s}$, corresponding to a one-year flood, whereas the maximum discharge capacity reaches up to $240 \mathrm{~m}^{3} / \mathrm{s}$ [28].

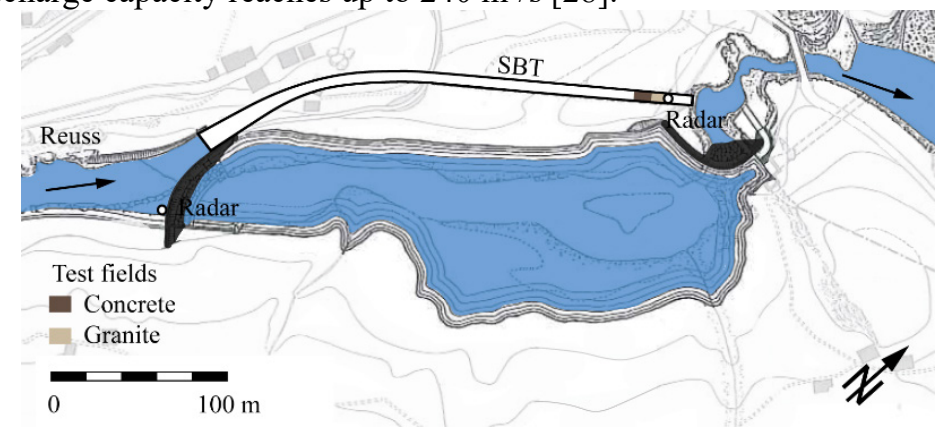

Fig. 1. Plan view of the Pfaffensprung SBT (courtesy of [25]). 


\subsection{Field test setup}

Two $4.4 \mathrm{~m}$ wide and $10 \mathrm{~m}$ long test fields were implemented at the Pfaffensprung SBT (Fig. 1). One test field consists of Urner granite, the other one of high-strength concrete. The granite pavement features $0.3 \mathrm{~m}$ thick and $1 \mathrm{~m}^{2}$ large granite blocks. The other test field has a $0.3 \mathrm{~m}$ thick lining of high-strength concrete. The material properties of the materials are listed in Table 1.

Table 1. Material properties at the Pfaffensprung SBT; *values provided by the quarry

\begin{tabular}{ccccc}
\hline Material & $\rho_{c}\left[\mathrm{~kg} / \mathrm{m}^{3}\right]$ & $f_{c}\left[\mathrm{~N} / \mathrm{mm}^{2}\right]$ & $f_{t}\left[\mathrm{~N} / \mathrm{mm}^{2}\right]$ & $Y_{M}{ }^{*}\left[\mathrm{kN} / \mathrm{mm}^{2}\right]$ \\
\hline Concrete & 2460 & 108 & 11.3 & 38.6 \\
Granite & $2650^{*}$ & $260^{*}$ & $10^{*}$ & 59.0 \\
\hline
\end{tabular}

The SBT and river discharges were continuously monitored by radar sensors installed in the SBT and at the reservoir head, respectively (Fig. 1). The abrasion of the test fields was determined annually from several overlapping 3D laser scans. Data processing was done by using the software "Z + F LaserControl ${ }^{\circledR}$ ", "Geomagic Studio ${ }^{\circledR}$ " and "Geomagic qualify ${ }^{\circledR}$. The uncertainty of a single measurement point amounts to $\pm 3 \mathrm{~mm}$. However, the error of the averaged abrasion depth is smaller than that as the fluctuations around the effective value are balanced out.

\section{Results}

\subsection{Abrasion rates and patterns}

The high-resolution abrasion map of the concrete is shown in Fig. 2a. It reveals a smoothly undulating abrasion pattern with larger abrasion depths on the orographic right tunnel side. This abrasion concentration is clearly represented by the cross-sectional abrasion profiles in Fig. 2b, showing the temporal and transverse evolution of the abrasion. The abrasion depths increase over time due to increasing bedload transport mass from 2012 to 2015. The maximum abrasion depth after the first operational year (2012) occurred at $y=1.6 \mathrm{~m}$ indicating the location of high bed shear stresses [7]. This is attributed to the effect of Prandtl's first type of secondary currents [29]. A spiral flow driven by centrifugal forces redistributes the bed shear stresses in spanwise direction, causing a concentration of sediment transport and hence of abrasion at the inner side of the bend. This initiates the formation of an abrasion channel, which in return stabilizes the secondary currents. With increasing operation duration, more sediment is transported and concentrated in this channel, resulting in a continuous abrasion process and hence amplification of the initial abrasion pattern from 2012 to 2015. The mean (i.e. spatially-averaged) abrasion depths increased approximately linearly with increasing cumulative bedload mass for the four-year period of measurement data at SBT Pfaffensprung [25]. This agrees with the observations of $[6,16]$. Over time the maximum abrasion depth moves towards the inner tunnel wall (Fig. 2b). The effect of the tunnel bend on bedload transport and hence abrasion pattern propagates in flow direction and is even visible at the outlet $180 \mathrm{~m}$ downstream of the bend (Fig. 2). The abrasion map after four operational years and a close-up picture of the granite are shown in Fig. 3a and b, respectively. In contrast to concrete with an evenly distributed abrasion pattern, granite mainly suffered from material losses along the longitudinal joints and upstream edges of the granite blocks (Fig. 3b). Abrasion was concentrated downstream of these initial damages. These abrasion characteristics confirm that abrasion is a self-intensifying process triggered by surface irregularities and structural weaknesses, which is in agreement with the findings from physical model investigations and other prototype observations [15, 30]. 
The mean abrasion depths of concrete and granite after four operational years are $a_{m}=31.0 \mathrm{~mm}$ and $a_{m}=5.3 \mathrm{~mm}$, respectively. This indicates that the abrasion resistance of granite is approx. six times higher compared to that of the high-strength concrete under the site-specific conditions existing in the Pfaffensprung SBT. The ratio between the maximum ( $=95 \%$-percentile value) and the mean abrasion depths of concrete and granite slightly differs with 1.8 and 2.1, respectively, due to the material-specific abrasion patterns.

a)

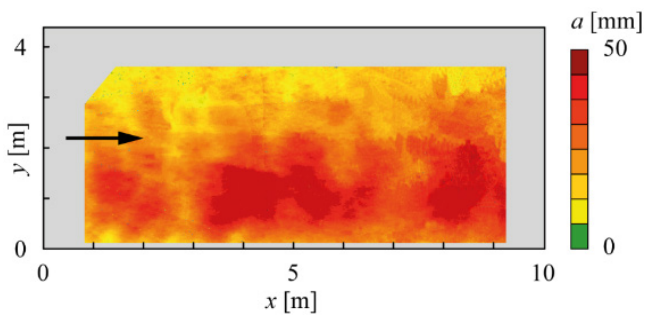

b)

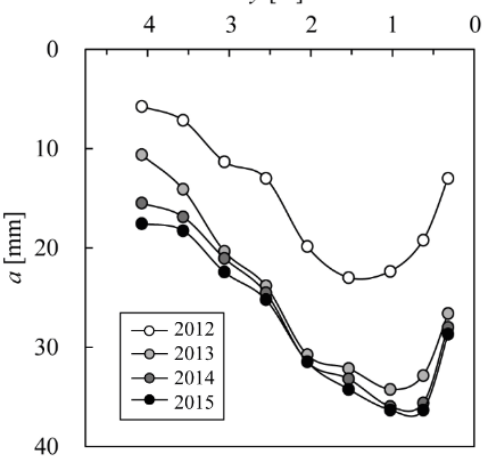

Fig. 2. Concrete test field with (a) high-resolution abrasion map after four operational years and (b) super-elevated cross-sectional abrasion profiles after one to four operational years averaged over the test field length.
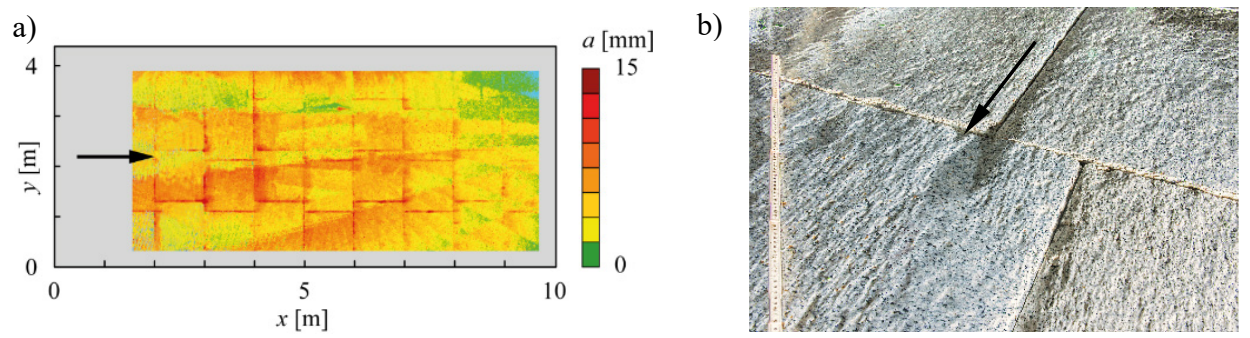

Fig. 3. Granite test field with (a) high-resolution abrasion map after four operational years and (b) closeup picture with abrasion concentrations at joints.

\subsection{Calibration of adapted abrasion model}

Bedload transport in the Reuss River was simulated with a 1D hydro-morphological numerical model [25]. Between 2012 and 2015 the mean annual bedload transport mass $(B L)$ in the Pfaffensprung SBT amounted to $350 \cdot 10^{3}$ tons ( $\pm 50 \%$ due to model uncertainty). The SBT is in operation 76 days per year on average. The $k_{v}$-values for high-strength concrete and granite were determined by applying these data together with the invert material parameters (Table 1) and abrasion data (Section 4.1) to the adapted saltation-abrasion model according to Auel et al. [14] (Equation (4)). It is noted that the cover effect term was neglected, since the transport capacity $q_{s}{ }^{*}$ largely exceeded the effective sediment transport rate $q_{s}$ and no depositions were observed in the Pfaffensprung SBT during the mentioned period.

The $k_{v}$-values for high-strength concrete and granite are $k_{v}=2.1 \cdot 10^{5}$ and $k_{v}=2.4 \cdot 10^{6}$, respectively. Fig. 4 presents these values as a function of tensile strength, together with the literature data $[8,15,16,31,32]$ and the value found by Auel et al. [14] for a concrete-lined SBT in Japan. The data show a general trend of increasing $k_{v}$ with increasing $f_{t}$, as revealed by Auel et al. [14] and a certain material-dependency of $k_{v}$. The highest $k_{v}$-values were 
obtained for rock (denoted by squares), followed by concrete (denoted by circles) and mortar / soft rock (denoted by diamonds and crosses). The $k_{v}$-value for the Urner granite implemented in the Pfaffensprung SBT agrees with Sklar and Dietrich's [5, 31] data for hard rocks such as granite, quartzite and marble. The value for high-strength concrete is in line with those obtained from literature for concrete and is only $10 \%$ higher than $k_{v}=1.9 \cdot 10^{5}$ found by Auel et al. [14]. This deviation might be caused by model uncertainties and the higher compressive strength and hence higher abrasion resistance of the Pfaffensprung concrete $\left(f_{c}=108 \mathrm{MPa}\right)$ compared to the concrete in the Japanese SBT ( $f_{c}=36$ and $70 \mathrm{MPa}$, respectively [14]). Only the data of Kryžanowski et al. [32] are significantly lower, which is likely attributed to the test location in a stilling basin where flow recirculations occur and cause repeating particle impacts, resulting in an increase of abrasion and hence decrease of $k_{v}$.

The fluctuation of $k_{v}$ around $k_{v} \approx 10^{5}$ for materials with $f_{t}>1 \mathrm{MPa}$ revealed by Auel et al. [14] cannot be identified in Fig. 4. This might be attributed to the effect of further influencing parameters of both the invert material and the sediment particles as reported in Section 1. More data are needed to establish a relation $k_{v}=\mathrm{f}\left(f_{t}\right)$.

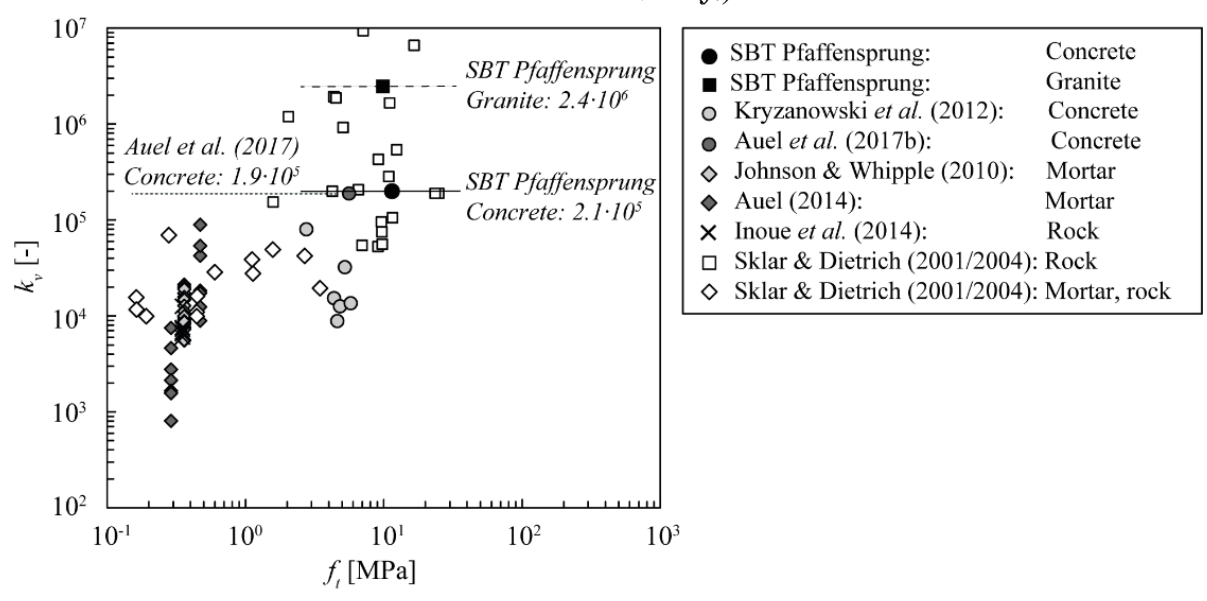

Fig. 4. Abrasion coefficient $k_{v}$ as function of tensile strength $f_{t}$ of our prototype data and literature data

\section{Conclusions}

Prototype investigations on hydro-abrasive erosion were performed and gave new insights into the abrasion patterns related to hydraulic and sediment transport conditions. We enlarged the application range of the adapted abrasion model to further invert materials, calibrated the abrasion coefficient and hence advanced abrasion modelling of concrete and natural rock in super-critical open channel flows over a fixed smooth and transitionally rough planar bed. This improves the understanding of bedrock incision and landscape evolution and contributes to a sustainable design and operation of hydraulic structures.

The abrasion coefficient $k_{v}$, a key parameter for abrasion prediction, was determined for the adapted saltation-abrasion model by Auel et al. [14] for high-strength concrete and granite using prototype data from the Swiss Pfaffensprung SBT. The values are in line with the results obtained from literature and show a certain material-dependency. The value for granite was an order of magnitude higher than for high-strength concrete due to its higher resistance against hydro-abrasive erosion. Although these values are in a realistic range, the analysis is based on only four years of abrasion data, which is rather short compared to typical timescales of hydro-abrasive erosion of decades or even centuries. Therefore, extended observation durations to analyse the effect of increasing structural weakening and bed 
roughness on flow structures, particle motion, hydroabrasion and their interaction are needed for a reliable determination of $k_{v}$ and a realistic long-term abrasion prediction.

ACKNOWLEDGEMENTS - The authors would like to express their sincere gratitude to the Swiss Federal Railway $S B B$ for supporting the prototype study and to Swisselectric Research, the Swiss Federal Office of Energy SFOE, the electric utility of Zurich ewz, the association of the Swiss cement industry Cemsuisse and the Lombardi Foundation for their financial support of the research project. The project was embedded in the Swiss Competence Center for Energy Research - Supply of Electricity (SCCER-SoE) framework.

\section{References}

1. Walling D. E., Webb B. W. (1996). Erosion and sediment yield: A global overview. Proc. IAHS Publications-Series of Proceedings and Reports-Intern Association Hydraulical Sciences 9: 2911-2921.

2. Syvitski J. P. M. (2003). Supply and flux of sediment along hydrological pathways: research for the $21^{\text {st }}$ century. Global and Planetary Change 39 (1): 1-11. DOI: 10.1016/S0921-8181(03)00008-0.

3. Anselmetti F. S., Bühler R., Finger D., Girardclos S., Lancini A., Rellstab C., Sturm M. (2007). Effects of Alpine hydropower dams on particle transport and lacustrine sedimentation. Aquatic Sciences 69 (2): 179-198.

4. Jacobs F., Winkeler W., Hinkeler F., Volkart P. (2001). Betonabrasion im Wasserbau ('Concrete abrasion at hydraulic structures'). VAW-Mitteilung 168 (H.-E. Minor, ed.), ETH Zurich, Switzerland, (in German).

5. Sklar L. S., Dietrich W. E. (2004). A mechanistic model for river incision into bedrock by saltating bed load. Water Resources Research 40 (6). DOI: W06301

6. Beer A. R., Turowski J. M. (2015). Bedload transport controls bedrock erosion under sediment-starved conditions. Earth Surface Dynamics 3: 291-309.

7. Ishibashi T. (1983). Hydraulic study on protection for erosion of sediment flush equipments of dams. Civil Society 334 (6): 103-112 (in Japanese).

8. Johnson J. P. L., Whipple K. X. (2010). Evaluating the controls of shear stress, sediment supply, alluvial cover, and channel morphology on experimental bedrock incision rate. Journal of Geophysical Research-Earth Surface 115. DOI: F02018

9. Uetz H. (1986). Abrasion und Erosion ('Abrasion and erosion'). Verlag Carl Hanser, München, Germany (in German).

10. Wellinger K., Uetz H. (1955). Gleitverschleiß, Spülverschleiß, Stahlverschleiß unter der Wirkung von körnigen Stoffen ('Sliding, flushing and jetting wear under the impact of granular materials'). VDI-Verlag, (in German).

11. Clark S. P. (1966). Handbook of physical constants. 97, Geological Society of America.

12. Sklar L. S., Dietrich W. E. (2012). Correction to "A mechanistic model for river incision into bedrock by saltating bed load". Water Resources Research 48 (6). DOI: W06301.

13. Auel C., Albayrak I., Sumi T., Boes R. M. (2017a). Sediment transport in high-speed flows over a fixed bed: 1. Particle dynamics. Earth Surface Processes and Landforms. DOI: $10.1002 /$ esp.4128.

14. Auel C., Albayrak I., Sumi T., Boes R. M. (2017b). Sediment transport in high-speed flows over a fixed bed: 2. Particle impacts and abrasion prediction. Earth Surface Processes and Landforms. DOI: 10.1002/esp.4132.

15. Auel C. (2014). Flow charachteristics, particle motion and invert abrasion in sediment bypass tunnels. VAW-Mitteilungen 229 (R. Boes, ed.), ETH Zurich, Switzerland. 
16. Inoue T, Izumi N, Shimizu Y, Parker G. (2014). Interaction among alluvial cover, bed roughness, and incision rate in purely bedrock and alluvial bedrock channel. Journal of Geophysical Research: Earth Surface 119 (10): 2123-2146.

17. Turowski J. M., Böckli M., Rickenmann D., Beer A. R. (2013). Field measurements of the energy delivered to the channel bed by moving bed load and links to bedrock erosion. Journal of Geophysical Research: Earth Surface 118 (4): 2438-2450.

18. Whipple K. X., Tucker G. E. (1999). Dynamics of the stream-power river incision model: Implications for height limits of mountain ranges, landscape response timescales, and research needs. Jl. of Geophysical Research-Solid Earth 104 (B8): 17661-17674.

19. Turowski, J. M. (2009). Stochastic modeling of the cover effect and bedrock erosion. Water Resources Research 45: W03422.

20. Beyeler J. D., Sklar L. S. (2010). Bedrock resistance to fluvial erosion: the importance of rock tensile strength, crystal grain size and porosity in scaling from the laboratory to the field. AGU Fall Meeting: Abstract EP41D-0740.

21. Momber A. (2014). Effects of target material properties on solid particle erosion of geomaterials at different impingement velocities. Wear 319 (1): 69-83.

22. Scheingross J. S., Brun F., Lo D. Y., Omerdin K., Lamb M. P. (2014). Experimental evidence for fluvial bedrock incision by suspended and bedload sediment. Geology 42 (6): 523-526.

23. Lamb M. P., Finnegan N. J., Scheingross J. S., Sklar L. S. (2015). New insights into the mechanics of fluvial bedrock erosion through flume experiments and theory. Geomorphology (244): 33-55.

24. Small E. E., Blom T., Hancock G. S., Hynek B. M., Wobus C. W. (2015). Variability of rock erodibility in bedrock-floored stream channels based on abrasion mill experiments. Journal of Geophysical Research: Earth Surface 120 (8): 1455-1469.

25. Müller-Hagmann, M. (2018). Hydroabrasion by high-speed sediment-laden flows in sediment bypass tunnels. VAW-Mitteilungen 239 (R. Boes, ed.). Also published as a Doctoral Thesis. Nr. 24291, ETH Zurich. ETH Zurich, Switzerland (in preparation).

26. GEWISS (2014). Gewässerinformationssystem ('Water information system'). Federal Authorities of Switzerland. Access 26.3.2012, from http://gewiss.admin.ch/ Gewiss internet/gewiss v5 0 internet/de/viewer.htm (in German).

27. SBZ (1943). Rekonstruktion des Umleittunnels am Pfaffensprung des Kraftwerks Amsteg der SBB ('Reconstruction of the bypass tunnel Pfaffensprung of the power plant Amsteg of the SBB'). Schweizerische Bauzeitung 121: 41-42 (in German).

28. Müller B., Walker M. (2015). The Pfaffensprung sediment bypass tunnel: 95 years of experience. Proc. First International Workshop on Sediment Bypass Tunnels, VAWMitteilungen 232 (R. Boes, ed.), VAW, ETH Zurich, Switzerland: 247-258.

29. Prandtl L. (1949). Führer durch die Strömungslehre ('Guide through fluid mechanics'). Vieweg und Sohn, Braunschweig, Germany (in German).

30. Jacobs F., Hagmann M. (2015). Sediment Bypass Tunnel Runcahez: Invert Abrasion 1995-2014. Proc. First International Workshop on Sediment Bypass Tunnels, VAWMitteilungen 232 (R. Boes, ed.), Zurich, Switzerland: 211-222.

31. Sklar L. S., Dietrich W. E. (2001). Sediment and rock strength controls on river incision into bedrock. Geology 29 (12): 1087-1090.

32. Kryžanowski A., Mikoš M., Šušteršič J., Ukrainczyk V., Planinc I. (2012). Testing of concrete abrasion resistance in hydraulic structures on the Lower Sava River. Strojniški vestnik - Journal of Mechanical Engineering 58 (4): 245-254. 